\title{
Thyroid lipomatosis in a 36-year-old patient with rheumatoid arthritis and a kidney transplant
}

\author{
Soledad Bell', Gabriela Alejandra Sosa', Ana del Valle Jaen ${ }^{2}$ and \\ María Fabiana Russo Picasso'
}

Departments of ${ }^{1}$ Endocrinology, Metabolism and Nuclear Medicine ${ }^{2}$ Pathology Hospital Italiano, Perón 4190, Buenos Aires, Argentina
Correspondence should be addressed to G A Sosa

Email

gabrielasosa208@gmail.com

\section{Summary}

Thyroid lipomatosis is a rare disease, as a total of 20 cases have been described in the literature. It is characterized by diffuse infiltration of the stroma by mature adipose tissue and by progressive growth that produces different degrees of compressive symptoms. Our aim is to present the case of a 36-year-old woman who consulted because of dyspnea caused by a multinodular goiter. She underwent surgery with the presumptive diagnosis of a malignant neoplasia, but the pathological examination of the surgical specimen established the diagnosis of thyroid lipomatosis.

\section{Learning points:}

- Thyroid lipomatosis is a rare, benign disease characterized by diffuse infiltration of the stroma by mature adipose tissue.

- The pathophysiology of diffuse proliferation of adipose tissue in the thyroid gland is unclear.

- Thyroid lipomatosis is clinically manifested by a progressive enlargement of the thyroid that can involve the airway and/or upper gastrointestinal tract, producing dyspnea, dysphagia, and changes in the voice.

- Given the rapid growth of the lesion, the two main differential diagnoses are anaplastic carcinoma and thyroid lymphoma.

- Imaging studies may suggest a differential diagnosis, but a definitive diagnosis generally requires histopathological confirmation after a thyroidectomy.

\section{Background}

Thyroid lipomatosis is a rare disease hither to described in only 20 patients. It is characterized by diffuse infiltration of mature adipose tissue in the thyroid gland, resulting in its progressive enlargement and potentially to the development of compressive symptoms. While some theories attempt to explain this disease's pathophysiology - such as through embryological origin of the adipose tissue, adipose metaplasia in response to hypoxia, or senile involution - the etiology of thyroid lipomatosis is not entirely clear. Imaging studies such as ultrasound, CT scan, and MRI may suggest the presence of adipose tissue in the gland, but a definitive diagnosis is confirmed by pathological study of the surgical specimen. In some cases, the diagnosis may be suggested by fine-needle aspiration (FNA) results.

\section{Case presentation}

We present a 36-year-old woman who was referred to an endocrinology clinic for dyspnea and goiter.

Her past medical history showed that she had epilepsy since childhood and that she was currently being treated with phenobarbital and lamotrigine. At age 14 years, she was diagnosed with rheumatoid arthritis, for which she had received treatment with glucocorticoids, methotrexate, gold salts, and infliximab. At age 

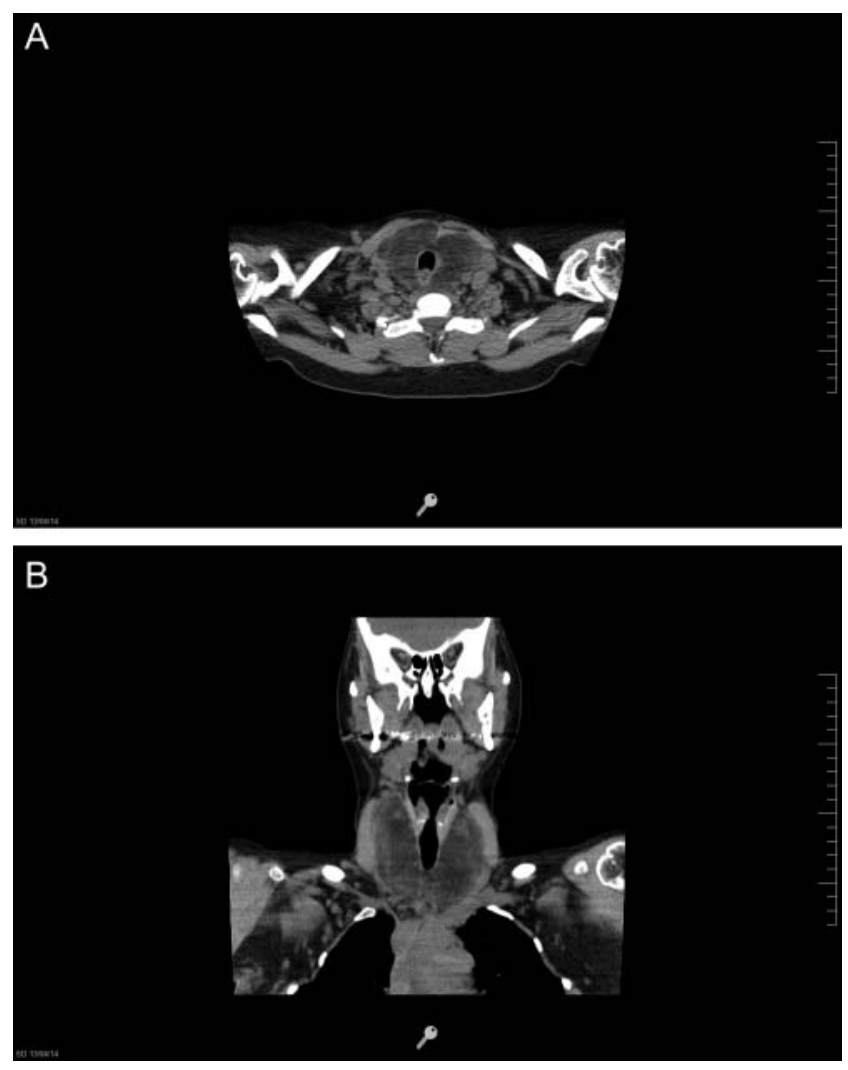

Figure 1

(A and B) Neck CT without contrast. Thyroid is diffusely enlarged, with low tomographic density, but greater than that of adipose tissue, with internal blood vessels and septations.

24 years, she was diagnosed with idiopathic bone marrow aplasia, which was treated with cyclosporine, antithymocyte globulin, and multiple blood transfusions. During a hospital admission for bone marrow aplasia, she developed nephrotic syndrome and renal failure. Her kidney biopsy showed secondary amyloidosis. At age 28 years, she started hemodialysis and underwent a splenectomy for splenomegaly of unknown etiology. Two months later, she underwent a kidney transplant with her mother as the donor. Since then, she received immunosuppressive therapy with methylprednisolone, tacrolimus and azathioprine. Her reproductive history showed a firsttrimester spontaneous abortion and a preterm delivery due to proteinuria at 34 weeks of gestation. The only relevant family history was her mother with hypothyroidism.

On admission, the patient reported dyspnea while in a supine position for the previous few nights. Her physical examination showed signs of exogenous hypercortisolism and bilateral cubital deviation of the first phalanges of her fingers. Her vital signs were normal. She presented with an enlarged nodular thyroid gland that was approximately
$80 \mathrm{~g}$ in mass, mobile, and nontender, with a clearly palpable $30 \mathrm{~mm}$ nodule in the right lobe and a $15 \mathrm{~mm}$ nodule in the left lobe. No lymphadenopathies were evident to palpation.

The notes in her case file showed that the patient had been assessed for a $60 \mathrm{~g}$ goiter 2 years before. A thyroid ultrasound showed a $21 \mathrm{~mm}$ multiloculated cystic nodule in the right lobe and a hyperechoic, $20 \mathrm{~mm}$ solid nodule with cystic areas in the left lobe. No lymph nodes were detected. Her laboratory tests at that time showed anemia and normal thyroid function. A FNA of the right lobe nodule indicated nodular hyperplasia (Bethesda category II) consistent with a benign nodule. Neck $\mathrm{X}$-rays did not show deviation of the trachea. The patient did not return for follow-up.

\section{Investigation}

A neck computed tomography (CT) scan was performed, showing a diffuse enlargement of the thyroid gland, predominantly of the right lobe. This enlargement invaded the prevertebral space up to the hyoid cartilage, displacing but not compressing the trachea. The thyroid also showed low tomographic density - still higher than that of adipose tissue - with internal blood vessels and septations (Fig. 1A and B). The routine laboratory workup and thyroid function tests were normal (Table 1).

\section{Treatment}

A total thyroidectomy was performed.

Table 1 Laboratory results.

\begin{tabular}{l}
\hline Parameters (NV) \\
\hline Hematocrit (37-47\%) \\
Hemoglobin $(11.5-16 \mathrm{~g} / \mathrm{dl})$ \\
White blood cells $\left(5000-10000 / \mathrm{mm}^{3}\right)$ \\
Glycaemia $(70-110 \mathrm{mg} / \mathrm{dl})$ \\
Creatinine $(0.5-1.2 \mathrm{ng} / \mathrm{dl})$ \\
Sodium $(135-145 \mathrm{mmol} / \mathrm{l})$ \\
Potassium $(3.5-5 \mathrm{mmol} / \mathrm{l})$ \\
Total bilirubin $(0.1-1.4 \mathrm{ng} / \mathrm{dl})$ \\
Alkaline phosphatase $(31-100 \mathrm{UI} / \mathrm{l})$ \\
Aspartate aminotransferase (AST, 10-42 UI/l) \\
Alanine aminotransferase (ALT, 10-40 UI/l) \\
Albumin $(3.2-5 \mathrm{~g} / \mathrm{dl})$ \\
Calcium $(8.5-10.5 \mathrm{mg} / \mathrm{dl})$ \\
Phosphorus $(2.5-4.5 \mathrm{mg} / \mathrm{dl})$ \\
Magnesium $(1.7-2.2 \mathrm{mg} / \mathrm{dl})$ \\
Thyrotropin $(0.47-4.64 \mathrm{mU} / \mathrm{ml})$ \\
Free thyroxine $(0.7-1.8 \mathrm{ng} / \mathrm{dl})$ \\
Anti-TPO $(0.9 \mathrm{Ul} / \mathrm{ml})$ \\
Pl
\end{tabular}

\begin{tabular}{c}
\hline Results \\
\hline $36.5 \%$ \\
$11.8 \mathrm{~g} / \mathrm{dl}$ \\
$7920 / \mathrm{mm}^{3}$ \\
$86 \mathrm{mg} / \mathrm{dl}$ \\
$0.89 \mathrm{ng} / \mathrm{dl}$ \\
$139 \mathrm{mmol} / \mathrm{l}$ \\
$4.6 \mathrm{mmol} / \mathrm{l}$ \\
$0.3 \mathrm{ng} / \mathrm{dl}$ \\
$139 \mathrm{Ul} / \mathrm{l}$ \\
$14 \mathrm{Ul} / \mathrm{l}$ \\
$9 \mathrm{Ul} / \mathrm{l}$ \\
$4 \mathrm{~g} / \mathrm{dl}$ \\
$9.4 \mathrm{mg} / \mathrm{dl}$ \\
$3.1 \mathrm{mg} / \mathrm{dl}$ \\
$1.5 \mathrm{mg} / \mathrm{dl}$ \\
$0.8 \mathrm{mU} / \mathrm{ml}$ \\
$1 \mathrm{ng} / \mathrm{dl}$ \\
$0.9 \mathrm{Ul} / \mathrm{ml}$ \\
\hline
\end{tabular}

NV, normal values; anti-TPO, anti-thyroperoxidase antibody. 


\section{Outcome and follow-up}

The pathology results were as follows. Macroscopic examination showed that the thyroid gland had a mass of $144 \mathrm{~g}$ and measured $98 \times 95 \times 45 \mathrm{~mm}$ (length $\times$ width $\times$ depth). The section surface of the right lobe showed a soft, pale, greyish-yellow tissue with a cystic area of $20 \times 10 \mathrm{~mm}$. The left lobe showed similar characteristics with a cystic area of $21 \times 20 \mathrm{~mm}$ (Fig. 2A). Microscopic examination revealed that normal thyroid tissue was replaced by mature adipose tissue except for a small remnant of medium-sized normal thyroid follicles containing colloid and lined by a single layer of cuboidal follicular cells (Fig. 2B). A pale, pink, amorphous material was deposited in the extracellular space and surrounded the thyroid follicles, which showed an apple-green birefringence in polarization microscopy with Congo red staining and positive immunostaining for amyloid A (Fig. 2C). The diagnosis of thyroid lipomatosis and amyloidosis was established.

Levothyroxine was started at a dose of $100 \mu \mathrm{g} /$ day orally.

\section{Discussion}

Thyroid lipomatosis is a rare, benign disease characterized by the enlargement of the thyroid produced by mature adipose tissue diffusely infiltrating the stroma. Only 20 cases have been reported in the literature (Table 2), 18 of which were confirmed by pathological examination. This disease does not show gender predominance (11 males and nine females), and while it affects mostly middle-aged patients (mean age at diagnosis: 44 years), it encompasses patients with a wide range of ages (11-77 years).

In normal thyroids, adipose tissue is distributed under the capsule and along vessels. Fat-containing lesions of the thyroid are seen as lesions containing macroscopic mature fat or lesions rich in microscopic intracellular fat vacuoles, or lesions that are referred to as clear cell or lipid-rich neoplasms (1). Clear cell changes can occur in thyroid neoplasms of various microscopic types and as a consequence of a variety of mechanisms, which include cytoplasmic vesicles (of mitochondrial, reticulum endoplasmic, or Golgi origin) and accumulation of glycogen, lipid, thyroglobulin or mucin (2).

The amount of adipose tissue in the thyroid can be increased in certain disorders, such as Hashimoto's thyroiditis, amyloid goiter containing adipose infiltration, heterotopic adipocytes, intrathyroidal thymus, and parathyroid lipoma. Some malignant thyroid lesions, such as encapsulated papillary thyroid carcinoma and thyroid liposarcoma or benign lesions, such as thyroid
A

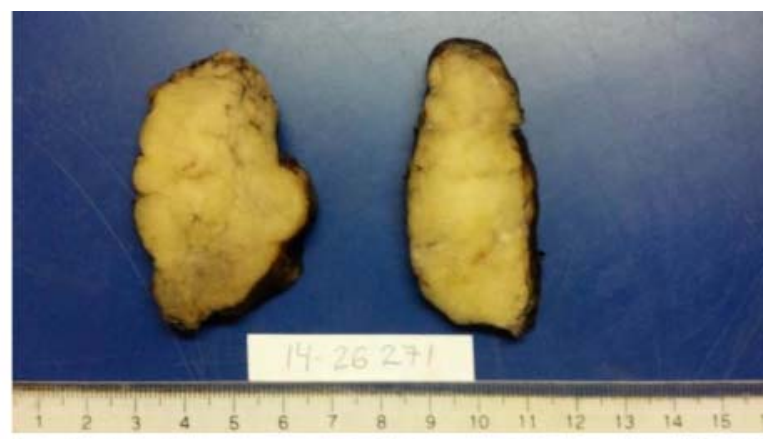

B

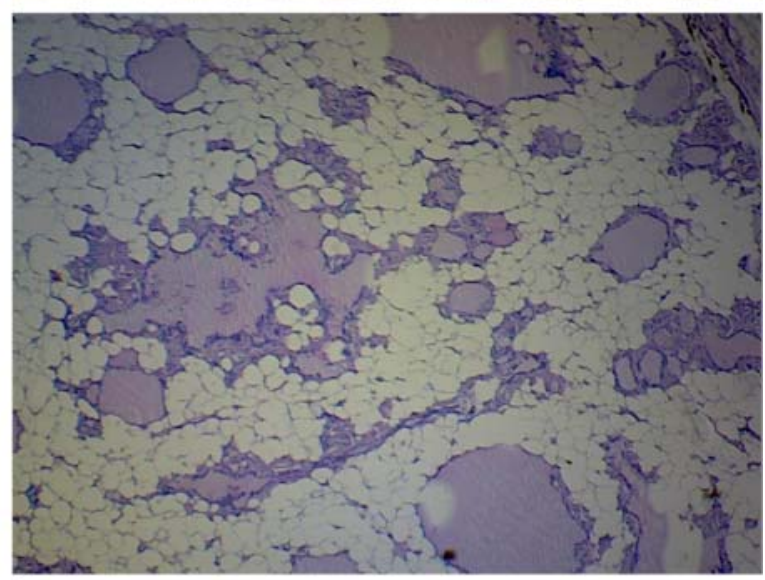

C

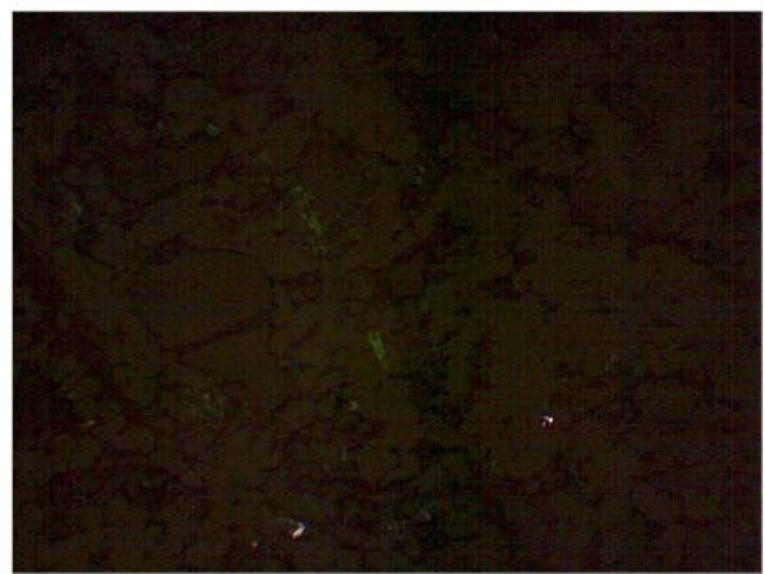

Figure 2

Pathology results. (A) Macroscopy: pale, greyish-yellow tissue.

(B) Microscopy $(40 \times)$ : Presence of mature adipose tissue with remaining normal thyroid follicles $(C)$ Microscopy $(40 \times)$ : positive Congo red staining.

adenolipoma or thyroid lipoma, can also be associated with increased intrathyroidal adipose content. Thyroid lipomas are characterized by the presence of a capsule, which is absent in diffuse thyroid lipomatosis and is the main differentiating feature (3).

The pathophysiology of diffuse proliferation of adipose tissue in the thyroid gland is unclear. Some authors suggest that heterotopic groups of fat cells are included in the thyroid gland during embryogenesis, 
.

DOI: 10.1530/EDM-16-0007

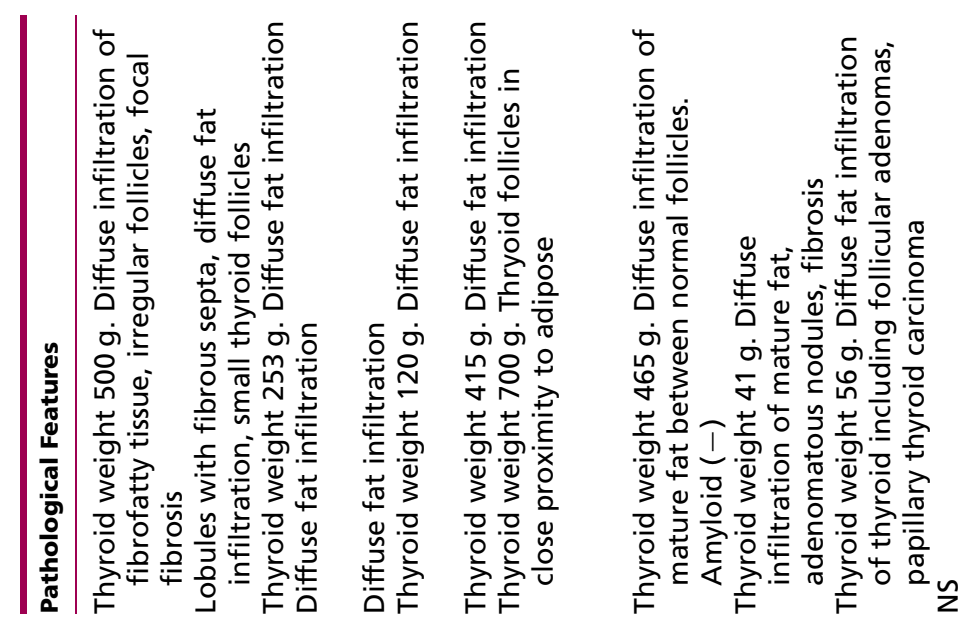

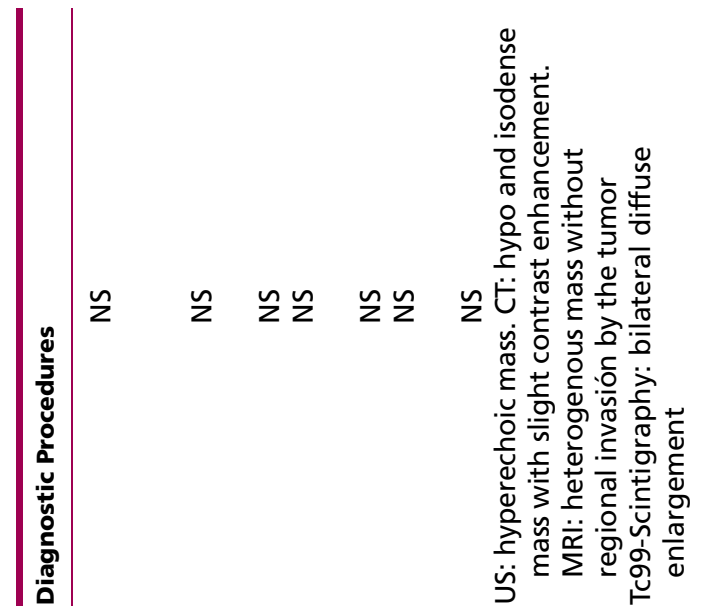

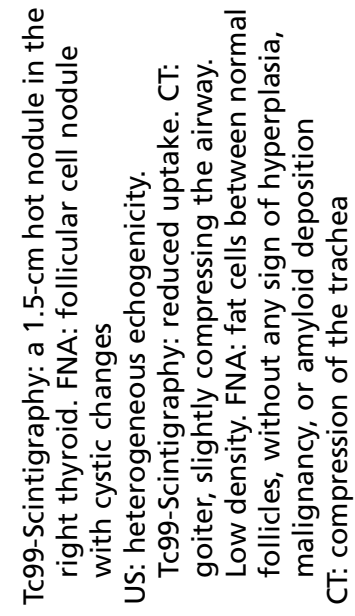

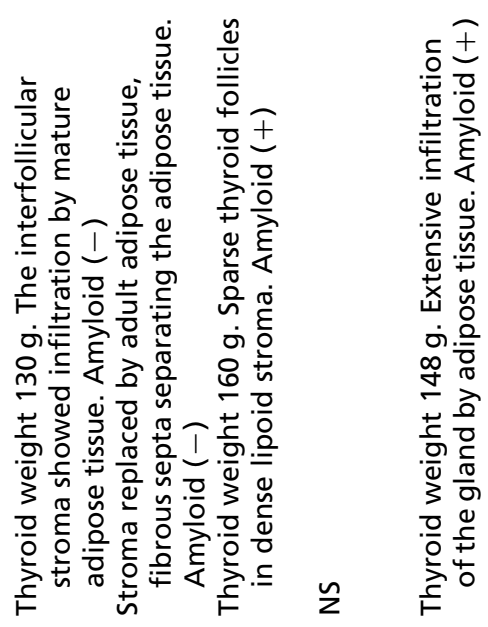

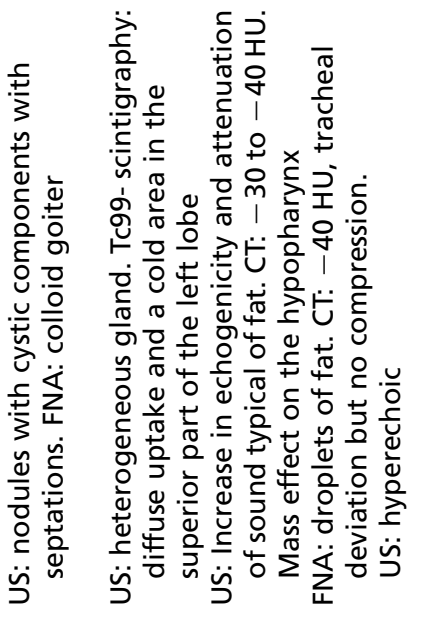

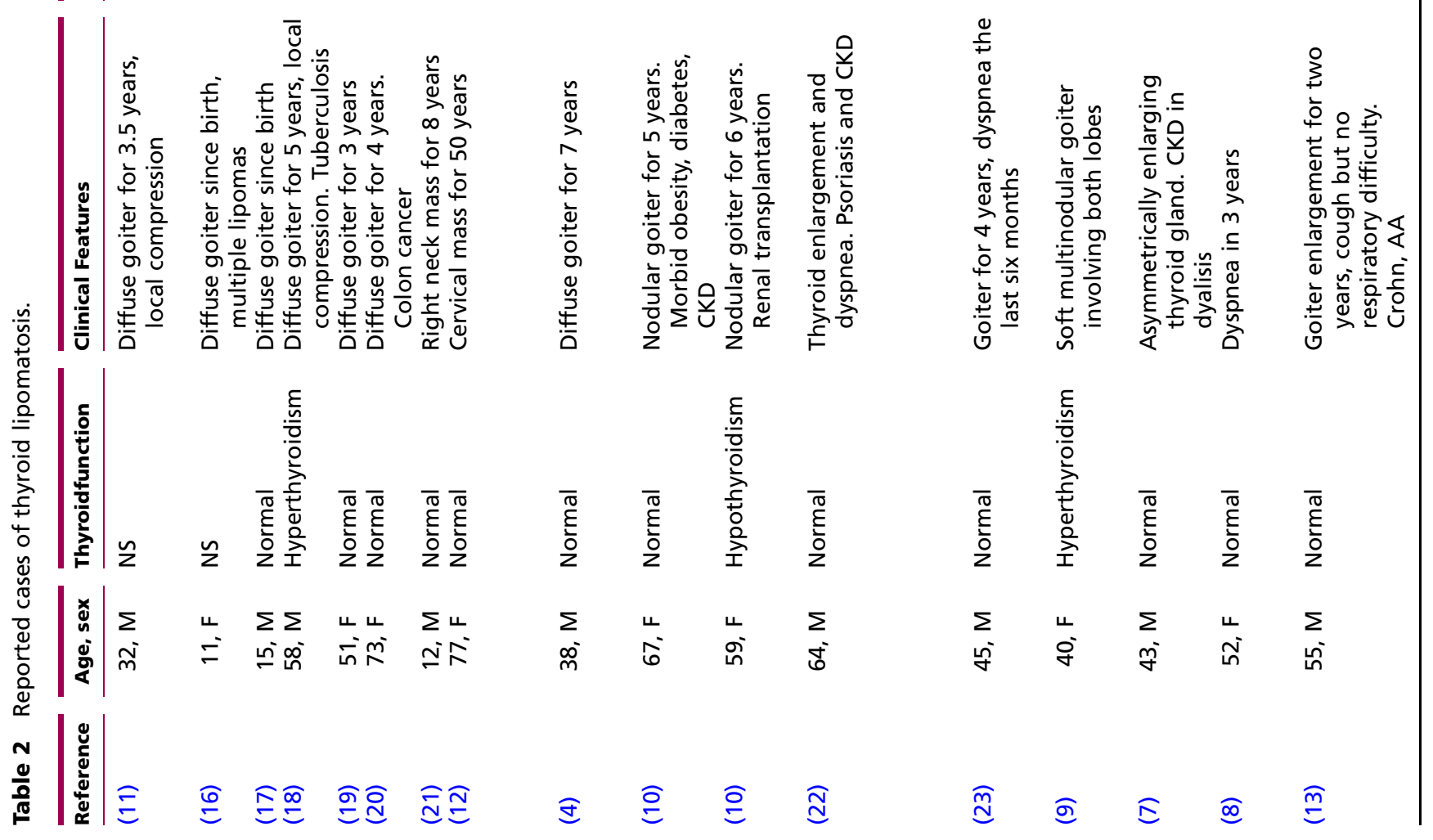




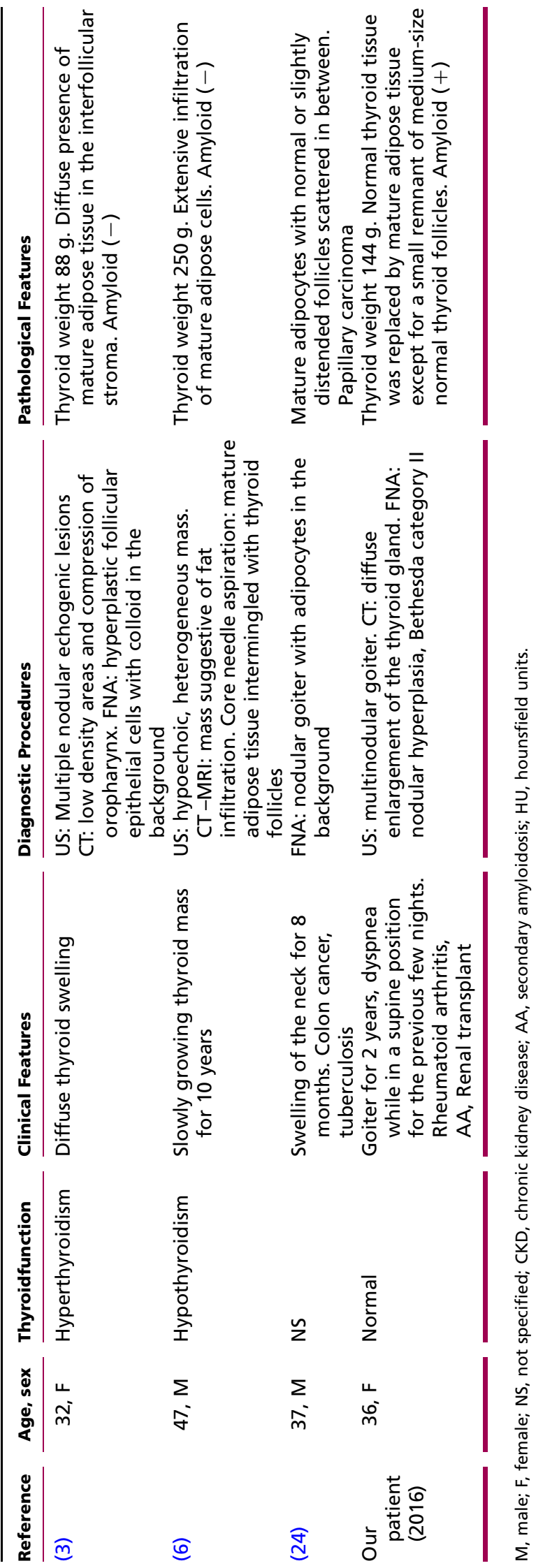

but others believe that a metaplasia from stromal fibroblasts is produced in response to hypoxia or senile involution $(4,5)$. Lau et al. (6) have recently published a possible relationship between the mutation of the mitochondrial protein succinate dehydrogenase-subunit $B$ and the abnormal differentiation of adipose tissue in thyroid lipomatosis.

Thyroid lipomatosis is clinically apparent due to a progressive enlargement of the thyroid that can involve the airway and/or upper gastrointestinal tract, producing dyspnea, dysphagia, and changes in the voice. Physical examination usually shows a soft, non-tender goiter that is nodular or diffuse (7). In most cases, tests show normal thyroid function, but both hyperthyroidism and hypothyroidism have been described in a few patients.

Given the rapid growth and the tumor size, the two main differential diagnoses, are anaplastic carcinoma and thyroid lymphoma. Imaging studies are helpful to establish the diagnosis. Ultrasound examination shows an enlarged thyroid with a diffuse increase of echogenicity and an echo attenuation typical of adipose tissue. CT scans show an enlarged thyroid with well-defined limits and diffuse infiltration by fat with negative density in the range of adipose tissue ( -30 to -40 Hounsfield units). Extension outside the thyroid bed can involve the upper mediastinum and the retropharyngeal compartment, compressing or displacing the surrounding airway and vascular structures (8).

FNA cytology can suggest a diagnosis of thyroid lipomatosis because it usually describes the presence of abundant fat cells among normal follicular cells (7). Although there are no clear guidelines to establish a diagnosis of thyroid lipomatosis with this method, the cytological findings are specific enough to exclude anaplastic carcinoma and thyroid lymphoma (9).

In a pathological examination, the thyroid reveals a section surface with a pale grey, yellowish, or tan color and, in some goiters, a focal cystic degeneration (10). Some of the published cases have reported massively enlarged thyroids with masses of 500-700 $g(11,12)$. Microscopic examination confirms the diffuse infiltration of mature adipose tissue among normal thyroid follicles. Fibrosis of the stroma and lymphocytic infiltration have also been occasionally described (10).

Our patient showed amyloid deposits, which had been previously reported in two patients with secondary amyloidosis associated with chronic renal failure and hemodialysis in one case, and with Crohn's disease and kidney transplant in the other $(7,13)$. Two other reports describe amyloid goiters with diffuse infiltration by adipose tissue $(14,15)$. The authors attribute the increase in size to 
amyloid deposits - in spite of the infiltration by fat - which underscores the lack of clear criteria to differentiate thyroid lipomatosis with amyloid deposits from amyloid goiters with fat infiltration. In our case, based on the pathology results that showed predominance of fat infiltration over amyloid content, we concluded that the amyloid deposit was secondary to the patient's systemic amyloidosis but that the increase in thyroid size was due to the infiltration by adipose tissue.

The aim of this paper was to describe a rare thyroid disease in a patient with secondary amyloidosis associated with rheumatoid arthritis and kidney transplantation. Although this association has already been reported, only a small number of cases have been described, and the relationship between these disorders remains unclear. It is important to underscore that the rapid growth and size of these lesions mandate a careful and prompt evaluation to exclude malignant diseases such as anaplastic carcinoma and thyroid lymphoma.

\section{Declaration of interest}

The authors declare that there is no conflict of interest that could be perceived as prejudicing the impartiality of the research reported.

\section{Funding}

This research did not receive any specific grant from any funding agency in the public, commercial or not-for-profit sector.

\section{Patient consent}

Written informed consent has been obtained from the patient for publication of the case report and accompanying images.

\section{Author contribution statement}

S Bell and G A Sosa were responsible for the conception of the work and acquisition of the data, conducting the literature review, and were the authors of the draft and final manuscript. A $\vee$ Jaen was responsible for the acquisition, analysis and review of the pathological samples, and reviewed the draft and final manuscript. M F Russo Picasso was responsible for the conception of the work, interpretation of the data, critical revision and final approval of the manuscript. All authors have agreed to be accountable for all aspects of the work in questions related to the accuracy or integrity of any part of the work.

\section{References}

1 LiVolsi VA. Unusual tumors and tumor-like conditions of the thyroid. In: Surgical Pathology of the Thyroid. Major Problems in Pathology Series, vol. 22. Ch 15, pp. 323-350. Ed. LiVolsi VA, Philadelphia: WB Saunders, 1990
2 Rosai \& Ackerman's Thyroid Gland Surgical Pathology 10th edn, Ch 9 p. 519, Elsevier 2011.

3 Sanuvada RV, Chowhan AK, Rukmangadha N, Patnayak R, Yootla M \& Amancharla LY 2014 Thyrolipomatosis: an inquisitive rare entity. Gland Surgery 3 6-9.

4 Arslan A, Alic B, Uzunlara AK, Buyukbayrama H \& Sarı I 1999 Diffuse lipomatosis of thyroid gland. Auris, Nasus, Larynx 26 213-215. (doi:10.1016/S0385-8146(98)00049-2)

5 Schroder S \& Bocker W 1985 Lipomatous lesions of the thyroid gland: a review. Applied Pathology 3 140-149.

6 Lau E, Freitas P, Costa J, Batista R, Máximo V, Coelho R, Matos-Lima L, Eloy C \& Carvalho D 2015 Loss of mitochondrial SDHB expression: what is its role in diffuse thyroid lipomatosis? Hormone and Metabolic Research 47 165-167. (doi:10.1055/s-0034-1398559)

7 Gonulalan G, Esen H, Erikoglu M \& Cakir M 2012 Thyroid lipomatosis. Internal Medicine 51 3383-3385. (doi:10.2169/internalmedicine.51.6765)

8 Lo R \& Donaldson C 2013 Diffuse lipomatosis of the thyroid gland. Ultrasound Quarterly 29 253-254. (doi:10.1097/RUQ.0b013e3182a0ad95)

9 Pradeep PV, Kumar R, Ragavan M \& Ramakrishna BA 2010 Diffuse lipomatosis of thyroid with hyperthyroidism. Journal of Postgraduate Medicine 56 35-36. (doi:10.4103/0022-3859.62430)

10 Ge Y, Luna MA, Cowan DF, Truong LD \& Ayala AG 2009 Thyrolipoma and thyrolipomatosis: 5 case reports and historical review of the literature. Annals of Diagnostic Pathology 13 384-389. (doi:10.1016/j. anndiagpath.2009.08.003)

11 Dhayagude RG 1942 Case report: massive fatty infiltration in a colloid goiter. Archives of Pathology 33 357-360.

12 Paoletti H, Tourette JH, Terrier JP, Colineau X, Thiebaut C, Dussaut JP, Pujol A, Muyard B, Nun P \& Solacroup JC 1997 Quid. Journal de Radiologie 78 1291-1294.

13 Jacques TA \& Sterns MP 2013 Diffuse lipomatosis of the thyroid with amyloid deposition. Journal de Radiologie 127 426-428.

14 Uzum G, Kaya FO, Uzum AK, Kucukyilmaz M, Gunes ME, Duzkoylu Y, Leblebici C, Koc O \& Sari YS 2013 Amyloid goiter associated with amyloidosis secondary to rheumatoid arthritis. Case Reports in Medicine 2013 1-3. (doi:10.1155/2013/792413)

15 Aksu AO, Ozmen MN, Oguz KK, Akinci D, Yasavun U \& Pinar Firat P 2010 Diffuse fatty infiltration of the thyroid gland in amyloidosis. Journal of Ultrasound in Medicine 29 1251-1255.

16 Simard LC 1945 Une nouvelle forme de goiter: La sclero-lympholipomatose thyroidienne. $L^{\prime}$ Union Medicale du Canada 74 884-891.

17 Chesky VE, Dreese WC \& Hellwig CA 1953 Adenolipomatosis of the thyroid: a new type of goiter. Surgery 34 38-45.

18 Bielicki F, Dawiskiba E, Kasprzak A, Kawecki K \& Zagrobelny Z 1968 Struma lipomatosa. Polski tygodnik lekarski 23 2018-2019.

19 Delforno S \& Donna A 1969 Lipomatosi diffusa della tiroide (Struma lipomatose). Cancro 22 613-617.

20 Asirwatham JE, Barcos M \& Shimaoka K 1979 Hamatomatous adiposity of thyroid gland. Journal of Medicine 10 197-206.

21 Simha MR \& Doctor VM 1983 Adenolipomatosis of the thyroid gland Indian Journal of Cancer 20 215-217.

22 Di Scioscio V, Loffreda V, Feraco P, Luccaroni R, Palena LM, Balbi T \& Zompatori M 2008 Diffuse Lipomatosis of Thyroid Gland. Journal of Clinical Endocrinology and Metabolism 93 8-9. (doi:10.1210/jc.2007-1667)

23 Gupta R, Arora R, Sharma A \& Dinda AK 2009 Diffuse lipomatosis of the thyroid gland: A pathologic curiosity. Indian Journal of Pathology and Microbiology 52 215-216.

24 Nandyala HS, Madapuram S, Yadav M \& Katamala SK 2015 Diffuse lipomatosis of the thyroid gland with papillary microcarcinoma: Report of a rare entity. Indian Journal of Pathology and Microbiology 58 348-350.

Received in final form 23 March 2016

Accepted 30 March 2016 